\title{
Neck telangiectasia: A case with a twist
}

\author{
Florica Sandru' ${ }^{1,2}$, Mihai Cristian Dumitrascu ${ }^{1,3}$, Ana Valea $^{4,5}$, \\ Anda Dumitrascu ${ }^{6}$, Mara Carsote ${ }^{1,6}$ \\ 1"Carol Davila" University of Medicine and Pharmacy, Bucharest, Romania \\ ${ }^{2}$ Elias Emergency University Hospital, Bucharest, Romania \\ ${ }^{3}$ Emergency University Hospital, Bucharest, Romania \\ ${ }^{4}$ Clinical County Hospital, Cluj-Napoca, Romania \\ 5"Iuliu Hatieganu" University of Medicine and Pharmacy, Cluj-Napoca, Romania \\ ${ }^{6}$ "C.I. Parhon" National Institute of Endocrinology, Bucharest, Romania
}

\begin{abstract}
Telangiectasia represents a sign on the skin underlining multiple conditions, characterised by red/purple/blue thin lines caused by dilatation of capillaries/arterioles/venules. Similar lesions may be detected during a surgical procedure at the surface of a solid organ. Pathological conditions associating the lesion are: dermatomyositis, scleroderma, lupus and the syndromes of ataxia-telangiectasia, respective hereditary hemorrhagic telangiectasia. We introduce a male case with anterior and lateral cervical enlargement with local skin changes of telangiectasia type. We introduce a male case with anterior and lateral cervical enlargement with local skin changes of telangiectasia type. The twist of the case is that, despite neck tegument red thin lines, the subject actually had a severe form of thyroid cancer. This is a case presentation. This is an 82 -year old non-smoker male from non-endemic area admitted for rapidly enlargement of a tumor mass at neck in addition with local skin changes like telangiectasia and erythema as well as speech, eating and breathing intermittent disturbances. Thyroid function was normal. Thyroid ultrasound showed an enlargement of right lobe, of 3.7 by 4 by $7 \mathrm{~cm}$ (centimeter), mostly displayed by a macronodule with mix structure, of oval shape, with extension to isthmus, which is well shaped, of 5.7 by 4 by $5.2 \mathrm{~cm}$. The data are highly suggestive for a thyroid cancer, thus the patient was further referred for total thyroidectomy. The changes of neck skin like telangiectasia and redness may exceptionally be caused by an aggressive thyroid cancer.
\end{abstract}

Keywords: telangiectasia, thyroid cancer, thyroid

\author{
Abbreviations \\ $\mathrm{A}-\mathrm{T}=$ ataxia-telangiectasia \\ $\mathrm{cm}=$ centimeter \\ $\mathrm{HHT}=$ hereditary hemorrhagic telangiectasia
}

\author{
FreeT4 $=$ thyroxine \\ 1131 = radioiodine \\ $\mathrm{TSH}=$ thyroid stimulating hormone
}

\section{INTRODUCTION}

Telangiectasia represents a sign on the skin underlining multiple conditions, characterised by red/ purple/blue thin lines caused by dilatation of capillaries/arterioles/venules $(1,2,3)$. The lines may isolated or in clusters $(1,2,3)$. Similar lesions may be detected during a surgical procedure at the surface of a solid organ (as seen on teguments, mostly on face, also named "spider veins") $(1,2,3)$. Usually telangiectasia is found in people who are more exposed to sun or they have a prolonged exposure to cold $(1,2,3)$. Dermatomyositis, scleroderma, lupus may associate the lesion $(1,2)$. Another type is generalized essential telangiectasia (of unknown cause) which is uncommon (3). Ataxia-telangiectasia (A-T) is an autosomal recessive syndrome of primary immunodeficiency type (mutations of a specific A-T gene that encodes a protein kinase involved in DNA pathways) (4). A part from neurological and dermatological anomalies there is an increased risk of different malignancies (4). The clinical picture is heterogeneous depending on severity (4). The congenital neurodegenerative disorder is onset mostly during childhood but late onset is also described (5). Another disorder is hereditary hemorrhagic telangiectasia (HHT or Osler-Weber-Rendu syndrome) which is an autosomal dominant condition (mostly $A C V R L 1$ or $E N G$ genes encoding bone morphogenetic protein receptor or SMAD4 gene is less frequent involved) 
involving the vessels of different organs thus associating a high risk of morbidity and mortality $(6,7)$. New drugs targeting angiogenetic pathways represent encouraging therapies $(6,7)$.

\section{AIM}

We introduce a male case with anterior and lateral cervical enlargement with local skin changes of telangiectasia type. The twist of the case is that, despite neck tegument red thin lines, the subject actually had a severe form of thyroid cancer.

\section{METHOD}

This is a case presentation.

\section{CASE DATA}

\section{Initial presentation}

This is an 82-year old non-smoker male from non-endemic area admitted for rapidly enlargement of a tumor mass at neck in addition with local skin changes like telangiectasia and erythema as well as speech, eating and breathing intermittent disturbances (Figure 1). He describes the changes since last severe months and he was seen by different medical departments. Also, non-specific posterior cervical pain is described by the subject. He associates high blood pressure which is controlled under oral medication, hyperlipemia and prostate adenoma. The medical family history is negative. He has not history of thyroid conditions and he was never evaluated from an endocrine point of view.

\section{Thyroid profile}

Thyroid function was normal based on TSH (Thyroid Stimulating Hormone) of $1.4 \mu \mathrm{UI} / \mathrm{ml}$
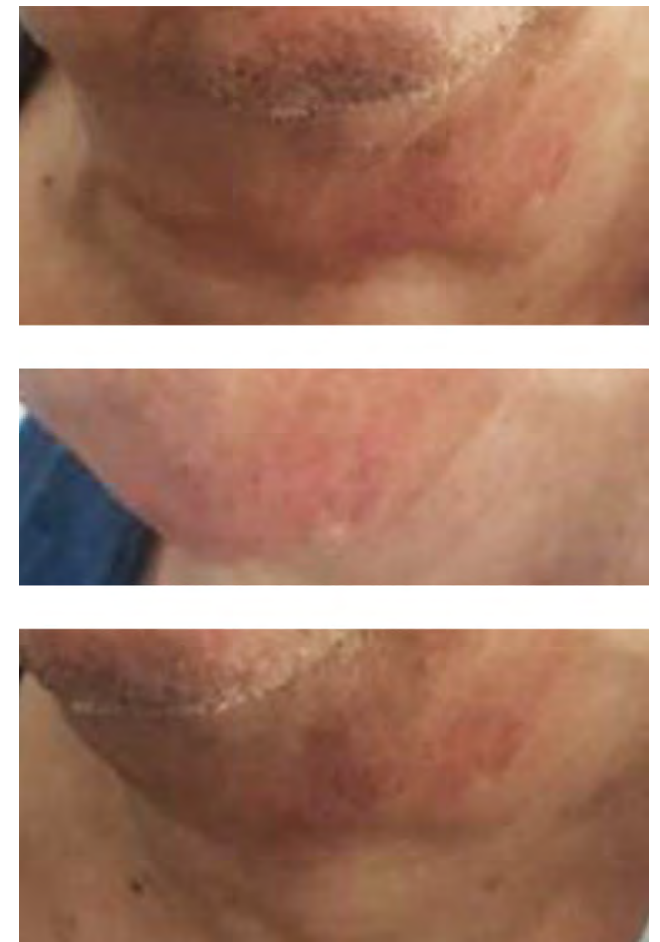

FIGURE 1. This is an 82-year old male with rapidly enlargement of a tumor mass at neck in addition with local skin changes like telangiectasia and erythema

(normal between 0.5 and $4.5 \mu \mathrm{UI} / \mathrm{ml}$ ), FreeT4 (thyroxine) of $14 \mathrm{pmol} / 1$ (normal between 10.3 and 24.4 pmol/l). The patient had negative antibodies like anti-thyroperoxidase antibobodies of $19 \mathrm{UI} / \mathrm{ml}$ (normal: 0-35 UI/ml) and, also, normal calcitonin (1 ng/ml, normal: $1-11 \mathrm{ng} / \mathrm{ml})$, parathormone (56 $\mathrm{pg} / \mathrm{ml}$, normal: 15-65 pg/ml). Thyroid ultrasound showed an enlargement of right lobe, of 3.7 by 4 by $7 \mathrm{~cm}$ (centimeter), mostly displayed by a macronodule with mix structure, of oval shape, with extension to isthmus, which is well shaped, of 5.7 by 4 by $5.2 \mathrm{~cm}$ (Figure 2). The left lobe (of 1 by 1.6 by $4 \mathrm{~cm}$ ) is homogenous, partially displayed by the

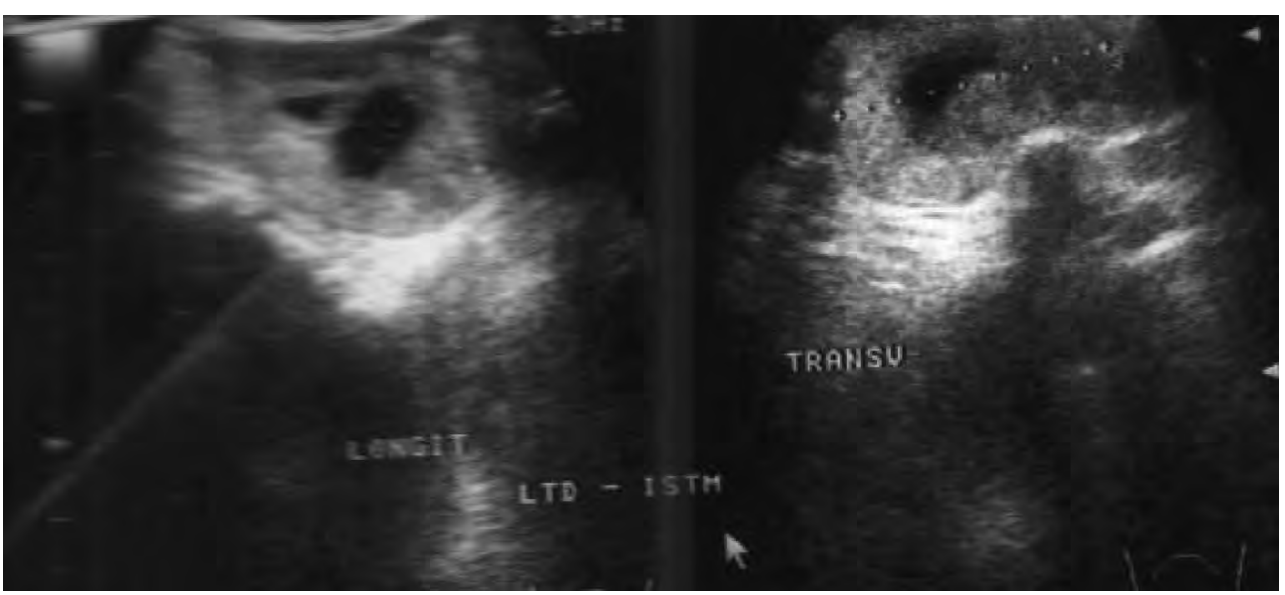

FIGURE 2. Thyroid ultrasound of an 82-year old male showing a macronodule with mix structure, of oval shape, with extension from the right lobe to the isthmus, which is well shaped, of 5.7 by 4 by $5.2 \mathrm{~cm}$ (longitudinal and transversal section) 
mentioned nodule, without local lymph nodes invasion based on ultrasound examination. Radioiodine $\mathrm{I}^{131}$ thyroid scintigram reveals an asymmetrical thyroid with inhomogeneous uptake of iodine and a "cold" nodule at the level of right lobe (Figure 3). The data are highly suggestive for a thyroid cancer, thus the patient was further referred for total thyroidectomy.

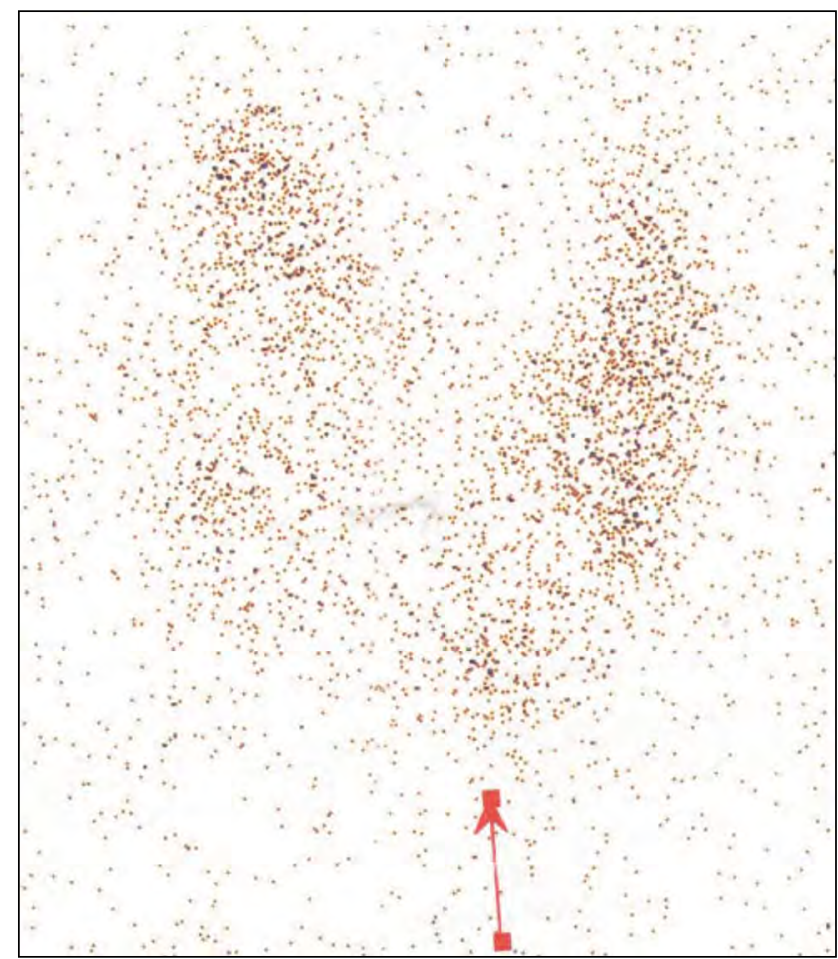

FIGURE 3. Radioiodine I $^{131}$ thyroid scintigram reveals an asymmetrical thyroid with inhomogeneous uptake of iodine and a "cold" nodule at the level of right lobe

\section{DISCUSSION}

Thyroid cancer local anomalies might be connected with the skin lesion due to local changes of small vessels status and/or necrosis and even associated infection. In this case, necrosis was not revealed by thyroid ultrasound. Of course, an accidental appearance of neck telangiectasia/eythema might be synchronous to thyroid neoplasia. Yet, the patient did not have it on face which is the typical location of the lesion for persons who are otherwise healthy. Limited data are published related to local tegument changes of thyroid cancer. Metastases at skin level have been described from differentiated thyroid cancer (8). Yet, mix follicular - papillary cancer and then anaplastic and poorly differentiated forms are the most aggressive $(9,10)$. Telangiectasia has been reported in severe conditions, as mentioned before, but the patient did not associate any suggestive disorder. Generally, the differentiated thyroid cancer has been associated with other neoplasia but no specific syndromes are described (11).

In this case the thyroid enlargement was progressive and recent. We had no records of prior thyroid nodules since the patient was not evaluated. The risk of malignancy in a thyroid incidentaloma varies from 5 to $25 \%(12,13)$. Long standing thyroid nodules underlining differentiated thyroid cancer may suffer a transformation to anaplastic type as dedifferentiation process in neuroendocrine neoplasia $(14,15)$. The risk of thyroid metastases is low (16). The patient had non-specific cervical and lumbar spine pain, most probably related to spondylarthrosis. Long term untreated hyperthyroidism may cause osteoporosis and associated low trauma vertebral fractures (including in males) but the thyroid function was normal in this particular case $(17,18)$. Thyroid cancers themselves are not associated with bone mass loss unless bone metastasis are positive which are not typical in papillary and follicular cancers (19).

Telangiectasia is a heterogeneous hallmark of different conditions. The patient also had local redness most probably related to local circulation anomalies. Among endocrine conditions, Cushing's syndrome may involve similar changes, a part of a more complex phenotype including plethora, striae, high body mass index, skin infections, etc. and the correction of persistent hypercortisolemia partially correct some of these $(20,21)$.

\section{CONCLUSION}

The changes of neck skin like telangiectasia and redness may exceptionally be caused by an aggressive thyroid cancer.

Conflict of interest: none declared Financial support: none declared

\section{REFERENCES}

1. https://www.merriam-webster.com/dictionary/telangiectasia.

2. https://www.hss.edu/conditions_telangiectasia-and-autoimmune-disease.asp.

3. Wiznia LE, Steuer AB, Penn LA, Meehan SA, Femia AN. Generalized essential telangiectasia. Dermatol Online J. 2018 Dec 15;24(12). pii: 13030/qt2926z3f5.
4. Amirifar P, Ranjouri MR, Yazdani R, Abolhassani H, Aghamohammadi A. Ataxia-telangiectasia: A review of clinical features and molecular pathology. Pediatr Allergy Immunol. 2019;30(3):277-288.

5. Levy A, Lang AE. Ataxia-telangiectasia: A review of movement disorders, clinical features, and genotype correlations. Mov Disord. 2018;33(8):1238-1247. 
6. Jackson SB, Villano NP, Benhammou JN, Lewis M, Pisegna JR Padua D. Gastrointestinal Manifestations of Hereditary Hemorrhagic Telangiectasia (HHT): A Systematic Review of the Literature. Dig Dis Sci. 2017;62(10):2623-2630.

7. Robert F, Desroches-Castan A, Bailly S, Dupuis-Girod S, Feige JJ. Future treatments for hereditary hemorrhagic telangiectasia. Orphanet J Rare Dis. 2020;15(1):4.

8. Cohen PR. Metastatic papillary thyroid carcinoma to the nose: Report and review of cutaneous metastases of papillary thyroid cancer. Dermatol Pract Concept. 2015;5(4):7-11.

9. Carsote M, Albu SE, lorgulescu R, Dumitrascu A, Terzea D, Goldstein A, Poiana C. From vasomotor symptoms to solid and insular papillary thyroid cancer with oxyphil variant areas. Journal of Surgical Sciences. 2015;2(2):87-91.

10. Huang J, Harris EJ, Lorch JH. Treatment of Aggressive Thyroid Cancer. Surg Pathol Clin. 2019;12(4):943-950.

11. Poiana C, Virtej I, Carsote M, Banceanu M, Sajin M, Stanescu B, loachim D, Hortopan D, Coculescu M. Virilising Sertoli-Leydig cell tumour associated with thyroid papillary carcinoma: Case report and general considerations, Gynecol Endocrinol 2010;26(8):617-622.

12. Dumitru N, Ghemigian A, Carsote M, Albu SE, Terzea D, Valea A. Thyroid nodules after initial evaluation by primary health care practitioners: An ultrasound pictorial essay. Archives of the Balkan Medical Union. 2016;51(3):434-438.

13. Gheorghisan-Galateanu AA, Carsote M, Valea A. Incidentaloma: From general practice to specific endocrine frame. J Pak Med Assoc. 2017; 67(6):917-922.
14. Poiana C, Neamtu MC, Avramescu ET, Carsote M, Trifanescu R, Terzea D, Neamtu OM, Danciulescu Miulescu R. The dedifferentiation of neuroendocrine tumor metastases: Myth or reality? Rom J Morphol Embryol. 2013; 54(1):201-3.

15. Poiana C, Neamţu MC, Avramescu ET, Carsote M, Trifanescu R, Terzea D, Neamtu OM, Ferechide D, Danciulescu Miulescu R. The poor prognosis factors in $\mathrm{G} 2$ neuroendocrine tumor. Rom J Morphol Embryol. 2013; 54(3 Suppl):717-20.

16. Poiana C, Carsote M, Ardeleanu C, Terzea D, Avramescu ET, Neamtu MC, Miulescu RD. The value of the immunohistochemistry in a case of gastric neuroendocrine tumor and thyroid metastasis. Rom J Morphol Embryol. 2011; 52(1):187-92.

17. Tsourdi $E$, Lademann $F$, Siggelkow $H$. Impact of thyroid diseases on bone. Internist (Berl). 2018;59(7):661-667.

18. Poiana C, V.Radoi, Carsote M, Bilezekian J. New Clues that May Link Osteoporosis to the Circulating Lipid Profile. Bone Research 2013; 1(3):260-266

19. Kondraciuk JD, Rice SL, Zhou X, Gharzeddine K, Knezevic A, Spratt DE, Sabra M, Larson SM, Grewal RK, Osborne JR. Thyroid Cancer Bone Metastasis: Survival and Genomic Characteristics of a Large Tertiary Care Cohort. Clin Nucl Med. 2019;44(8):e465-e471.

20. Paduraru DN, Nica A, Carsote M, Valea A. Adrenalectomy for Cushing's syndrome: Do's and don'ts. Journal of Medicine and Life. 2016;4(9):334-341.

21. Stratakis CA. Skin manifestations of Cushing's syndrome. Rev Endocr Metab Disord. 2016;17(3):283-286. 